\title{
Immediate outcome of balloon pulmonary valvuloplasty in children: Experience at ShahidGangalal National Heart Centre, Nepal
}

\author{
C M Adhikari ${ }^{1}$, M Shrestha ${ }^{1}, \mathbf{S}$ Thapaliya $^{1}$, U Shakya $^{1}$
}

Sri Lanka Journal of Child Health, 2014; 43(2): 97-99

\begin{abstract}
Introduction: Balloon pulmonary valvuloplasty (BPV) has become the treatment of choice for the relief of moderate to severe pulmonary stenosis (PS).
\end{abstract}

Objective: To assess the immediate outcome of BPV in children with congenital PS at Shahid Gangalal National Heart Centre (SGNHC), Kathmandu, Nepal.

Methods: A retrospective longitudinal cohort study was carried out in SGNHC from June 2006 to June 2013. Seventy consecutive patients (37 males) with moderate to severe PS who underwent balloon valvuloplasty were included in the study. The gradient was measured pre and immediate post valvuloplasty at catheterization and compared.

Results: After BPV, significant reductions in the right ventricular peak pressure from $111.3 \pm 43.2 \mathrm{mmHg}$ to $57.0 \pm 25.9 \mathrm{mmHg}(\mathrm{p}<0.001)$ and peak-to-peak systolic pressure gradient across the pulmonary valve from $76.5 \pm 25.1 \mathrm{mmHg}$ to $32.0 \pm 20.9 \mathrm{mmHg}(\mathrm{p}<0.001)$ were achieved. In $74.2 \%$ patients, peak-to-peak systolic pressure gradient across the pulmonary valve decreased below $35 \mathrm{mmHg}$. No major complication or mortality was noted.

Conclusions: The immediate outcome of balloon pulmonary valvuloplasty in children was excellent.

(Keywords: Pulmonary stenosis; balloon pulmonary valvuloplasty; children)

\section{Introduction}

Pulmonary stenosis (PS) accounts for about $10-12 \%$ of congenital heart disease ${ }^{1}$. Since the first description of balloon pulmonary valvuloplasty (BPV) in 1982 by Kan, the procedure has been extensively utilized by several groups of workers for relief of $\mathrm{PS}^{2}$. BPV has now become the treatment of choice for the relief of moderate and severe valvular PS in all age groups and has completely replaced surgical valvotomy ${ }^{3}$. It effectively reduces right ventricle-pulmonary artery systolic pressure gradient ${ }^{2}$. It should be considered as the treatment of choice for children with PS based on its excellent outcome, lesser trauma and fewer

${ }^{1}$ Department of Cardiology, Shahid Gangalal National

Heart Centre, Bansbari, Kathmandu, Nepal

(Received on 10 August 2013: Accepted after revision on 27 September 2013) complications ${ }^{4,5}$. It is generally recommended that the procedure be performed for peak-to-peak gradient in excess of $50 \mathrm{mmHg}^{6}$.

\section{Objective}

To evaluate the immediate results of BPV in children at Shahid Gangalal National Heart Centre (SGNHC), Kathmandu, Nepal

\section{Method}

This is a retrospective longitudinal cohort study of 70 consecutive patients who are less than 15 years old with moderate $(\geq 50 \mathrm{mmHg})$ and $\operatorname{severe}(\geq 70 \mathrm{mmHg})$ PS who underwent BPV with Tyshak balloon catheter at SGNHC over a period of 7 years from June 2006 to June 2013. Six cases were excluded from this study. Three cases were excluded as PS was associated with other cardiac anomalies (PDA in 2, ASD in 1). Three others were excluded as there was no balloon dilatation (unsuitable balloon size in 1 and inability to cross the pulmonary valve with the wire in 2). This study was approved by the ethical review board of SGNHC. The gradient was measured before and immediately after valvuloplasty. Data were collected by reviewing medical records, noninvasive studies and cardiac catheterization laboratory.

Technique of BPV: Vascular access was via femoral vein; right ventricular (RV) angiography was performed with a Berman balloon catheter in lateral view initially. Haemodynamic data, including RV pressure and pulmonary artery (PA) pressure were documented during catheterization with a Swan-Ganz catheter. Our technique of balloon dilatation of the pulmonary valve was similar to that described by Kan et $\mathrm{al}^{2}$; a long $\mathrm{J}$ tipped exchange guide wire $(260 \mathrm{~cm})$ was used to advance the balloon to the pulmonary valve site. Singleballoon technique was performed via femoral vein, with balloon size $15 \%$ greater than the pulmonary valve annulus diameter measured on 2D-Echo Doppler evaluation. Repeated balloon dilation 2-3times was performed and each inflation-deflation time was no more than 30 seconds. We define BPV a success if peak-topeak pressure gradient (PG) by pull back pressure tracing post BPV was $\leq 35 \mathrm{mmHg}$ immediately after the procedure. All patients were given heparin in a dose of 100 units per $\mathrm{kg}$ during the procedure. The patient usually stayed in hospital for one day after the procedure, received intravenous antibiotics and was discharged after performing 2D-Echo Doppler evaluation. 
Statistical analysis: All data were expressed as mean \pm SD or median with range. Paired t- test was used to compare the mean right ventricular pressure and pressure gradient across the pulmonary valve before and after the procedure. A $\mathrm{P}$ value less than 0.05 , was considered significant.

\section{Results}

Altogether 70 patients (37 male and 33 female) were included in this study. The ages ranged from 14 days to 15 years with a mean age of $8.7 \pm 4.2$ years. Three $(4.2 \%)$ cases had to undergo repeat procedure. Eight patients had moderate PS and 62 had severe PS. After BPV, there was a significant reduction in the right ventricular peak pressure (RVP), from $111.3 \pm 43.2 \mathrm{mmHg}$ to $57.0 \pm 25.9$ $\mathrm{mmHg}(\mathrm{p}<0.001)$. Peak-to-peak pressure gradient across the pulmonary valve decreased from $76.5 \pm 25.1 \mathrm{mmHg}$ to $32.0 \pm 20.9 \mathrm{~mm}-\mathrm{Hg}(\mathrm{p}<0.001)$. In $52(74.2 \%)$ patients, peak-to-peak systolic pressure gradient across pulmonary valve decreased below $35 \mathrm{mmHg}$. In 11 (15.8\%) patients it was above $35 \mathrm{mmHg}$ but below 50 mmHg. In only $7(10.0 \%)$ patients was it more than 50 $\mathrm{mmHg}$. There were no major complications, such as severe pulmonary regurgitation or death. All the patients were discharged the day after the procedure.

The demographic and clinical profile of the patients is shown in Table 1

Table 1

Demographic \& clinical profile of patients

\begin{tabular}{|l|c|}
\hline \multicolumn{1}{|c|}{ Character } & Number (\%) \\
\hline Mex & $37(52.8)$ \\
Female & $33(47.2)$ \\
\hline Pulmonary stenosis & $62(88.5)$ \\
Severe & $08(11.4)$ \\
Moderate & \\
\hline Age & $04(05.7)$ \\
$<1$ year & $06(08.6)$ \\
1 - 3 years & $05(07.2)$ \\
3 to 5 years & $55(78.5)$ \\
$>$ 5 years &
\end{tabular}

Comparison of pressures before and immediately after BPV is shown in Table 2.

Table 2

Comparison of pressures before and immediately after BPV

\begin{tabular}{|l|c|c|c|}
\hline & Pre BPV & Post BPV & p value \\
\hline Right ventricle peak pressure (mmHg) & $111.3 \pm 43.2$ & $57.0 \pm 25.9$ & $<0.001$ \\
\hline peak to peak pressure across pulmonary valve (mmHg) & $76.5 \pm 25.1$ & $32.0 \pm 20.9$ & $<0.001$ \\
\hline
\end{tabular}

Results based upon peak-to-peak pressure gradient across pulmonary valve are shown in Table 3 .

Table 3

Results based upon peak-to-peak pressure gradient across pulmonary valve

\begin{tabular}{|l|c|}
\hline \multicolumn{1}{|c|}{ Pressure gradient } & Number (\%) \\
\hline$\leq 35 \mathrm{mmHg}$ & $52(74.2)$ \\
\hline 36 to $50 \mathrm{mmHg}$ & $11(15.8)$ \\
\hline$>50 \mathrm{mmHg}$ & $07(10.0)$ \\
\hline
\end{tabular}

\section{Discussion}

PS is one of the common congenital heart diseases ${ }^{7}$. The traditional method of treatment was surgical valvotomy until 1982, when Kan et al introduced the technique of percutaneous balloon valvuloplasty ${ }^{2}$. Since then, it has replaced the surgical option ${ }^{3,8,9}$. Our study confirms the safety and effectiveness of BPV in children with PS.

The peak-to-peak pressure gradient across pulmonary valve decreased from $76.5 \pm 25.1 \mathrm{mmHg}$ to $32.0 \pm 20.9$ $\mathrm{mmHg}$ after BPV which is comparable to studies from other countries ${ }^{9,10,11}$.

A good outcome, defined as a residual catheter gradient $<36 \mathrm{mmHg}$, was achieved in $74.2 \%$ patients which is comparable to $77 \%$ in a similar study from $\operatorname{Iran}^{12}$. But when the residual pressure gradient $(\mathrm{PG})$ after $\mathrm{BPV}<25$ $\mathrm{mmHg}$ is considered successful as considered in Sri Lankan study ${ }^{11}$, our study showed $51.4 \%$ success rate which is slightly lower than their study $(60 \%)$.
In our study, procedure failure was mainly due to an inability to cross the pulmonary valve and unsuitable balloon similar to Sri Lankan study ${ }^{11}$.

In general, after BPV, there is a decrease of RV pressure ranging from 39 to $71 \%$ and peak pressure gradient across pulmonary valve ranging from 45 to $93 \%{ }^{13}$. In our study, there was a $50 \%$ decrease in RV pressure, and $62 \%$ reduction of peak pressure gradient across pulmonary valve after the procedure.

In our study there were no serious complications such as severe pulmonary regurgitation or annular laceration. Complications are common when balloon to annulus ratio exceeds $30 \%{ }^{14}$. However, in our study we used a balloon size about $25 \%$ greater than the annulus diameter.

\section{Conclusions}

The immediate outcomes of balloon pulmonary valvuloplasty in children are excellent. BPV is a safe, effective and reliable treatment for patients with PS and is the treatment of choice in patients with symptomatic pulmonary stenosis.

\section{References}

1. Wang JK, Wu MH, Lee WL, et al. Balloon dilatation for critical pulmonary stenosis. 
International Journal of Cardiology 1999; 69: $27-$ 32.

http://dx.doi.org/10.1016/S0167-5273(98)00380-5

2. Kan JS, White RI Jr, Mitchell SE, et al. Percutaneous balloon valvuloplasty: A new method for treating congenital pulmonary valve stenosis. New England Journal of Medicine 1982; 307:540-2. http://dx.doi.org/10.1056/NEJM198208263070907

3. Awni Al- Madani. Mid-term results of balloon pulmonary valvuloplasty in children at Queen Alia Heart Institute. Journal of the Royal Medical Services 2010; 17(2): 47-52

4. Maostafa BA, Seyed-Hossien M, Shahrokh R. Long-term Results of balloon pulmonary valvuloplasty in children with congenital pulmonary valve stenosis. Iranian Journal of Pediatrics 2013; 23(1):32-6.

5. Liu F, Wu L, Huang GY, Zhang LF, et al.Percutaneous balloon valvuloplasty for severe and critical pulmonary valve stenosis in infants under six months. Zhonghua yi xue za zhi 2009 5; 89(46): 3253-6.

6. Rao PS. Percutaneous balloon pulmonary valvuloplasty: state of the art. Catheterization and cardiovascular interventions : Journal of the Society for Cardiac Angiography \& Interventions 2007; 69(5):747-63.

http://dx.doi.org/10.1002/ccd.20982

7. Chen CR, Cheng TO, Huang T, et al. Percutaneous balloon valvuloplasty for pulmonic stenosis in adolescents and adults. New England Journal of Medicine 1996; 335:21-5. http://dx.doi.org/10.1056/NEJM199607043350104

8. Fawzy ME, Awad M, Galal O, et al. Long-Term results of pulmonary balloon valvuloplasty in adult patients. Journal of Heart Valve Disease 2001; 10(6):812-8.
9. Rao PS, Galal O, Patnana M, et al. Results of three to 10 year follow up of balloon dilatation of the pulmonary valve. Heart 1998; 80: 591-5.

10. Masura J, Burch M, Deanfield JE, et al. Five year follow-up after balloon pulmonary valvuloplasty. Journal of the American College of Cardiology1993; 21:132-3. http://dx.doi.org/10.1016/0735-1097(93)90727-I

11. Sunethra Irugal Bandara, Sinnathurai Narenthiran, Wijeyasingam Santharaj, Kanapathipillai Rajakanthan, Duminda Samarasinghe, et al. Short term results of balloon pulmonary valvuloplasty in children: a single centre study over a period of 42 months. Sri Lanka Journal of Child Health, 2011; 40: $13-15$. http://dx.doi.org/10.4038/sljch.v40i1.2862

12. AlirezaAhmadi, Mohammadreza Sabri. Percutaneous balloon valvuloplasty in patients with pulmonary valve stenosis: A single centre experiment. Journal Pakistan Medical Association 2012; 62(3 Suppl. 1):58-61.

13. Sir-Chen Lin, Juey-Jen Hwang, Kwan-Lih Hsu, Chii- Ming Lee,Jou-Kou Wang, Chuen-Den Tseng, et al . Balloon pulmonary valvuloplasty in adults with congenital valvular pulmonary stenosis. Acta Cardiologica Sinica 2004; 20:147-53.

14. Sharma R,Rajbhandari R, Limbu L, Singh S, Bhatta YKD, $\mathrm{KC} \mathrm{MB}$ et al. Balloon pulmonary valvuloplasty in patients with congenital valvular pulmonary stenosis. Nepalese Heart Journal 2012; 9(1):7-9. 